\title{
Opinions and activities of families regarding money management and saving awareness ${ }^{1}$
}

\author{
Handan Asûde Başal ${ }^{2}$ \\ Meral Taner Derman ${ }^{3}$
}

\begin{abstract}
In order to minimize today's financial problems, it is needed to increase the literacy levels of individuals starting from their childhood. Consequently, considering the fact that financial literacy is more effective when it is taught in early ages, families of 5-6 year old children going to preschool institutions need to determine the points to take into account regarding financial management and saving awareness. Through this purpose, a structured interview form was used with families of 945 children, 498 of whom are girls and 447 of whom are boys. Frequency and percentage calculations and chi square test were used in analyzing the data.

At the end of the research, it was determined that most of preschoolers had moneyboxes and few of them had saving accounts in banks and they received allowances. It was established that educational levels of families have great influence on children when they choose bank accounts or moneyboxes while socio-economical levels of families have influence on having a bank account. Majority of families stated that they try to set an example for their children on savings and ownership and they buy the stuff they children need, not they want. Likewise, most of the families stated that they try to teach their children how to trade economically and make a budget by going to markets and bazaars with them.
\end{abstract}

Keywords: Money management; financial literacy; money saving awareness; children; opinions

\section{INTRODUCTION}

Financial literacy helps individuals with financial problems of daily life and it is defined as the ability to manage savings, personal loans and credits and evaluate the investments in the long haul. In addition to this behaviors such as making a budget and making wise decisions get more important (Wagland, 2006).

Financial literacy has become more important in recent years with more complicated financial tools. Markets can only be run affectively by individuals with basic knowledge on financial concepts, tools and matters. To this respect, further studies to improve financial literacy levels of children may be effective in creating a better working environment for financial institutions in the future (Bayram, 2015).

\footnotetext{
${ }^{1}$ Paper has been presented on "1st International Conference on Lifelong Learning and Leadership for all"-ICLEL 2015. 2 Prof. Dr., Uludag University, Education Faculty Department of Elementary Teacher Training Preschool Education Program, asubasal@uludag.edu.tr

${ }^{3}$ Ph.D., Uludag University Education Faculty Department of Elementary Teacher Training Preschool Education Program, mtaner@uludag.edu.tr
} 
Başal, H. A., \& Taner Derman, M. (2016). Opinions and activities of families regarding money management and saving awareness. International Journal of Human Sciences, 13(1), 957-964. doi:10.14687/ijhs.v13i1.3639

Children acquire prior knowledge on production and consumption first in their families (Kır, 2010). Children observe the abilities and attitudes of their parents on saving, management and consumption of financial resources and develop attitudes on financial matters by taking their parents as models. Therefore, parents are very important for children to develop awareness on money management and saving (Çakmak and Çakır, 2013).

Parents must inform their children on money management and saving matters at early ages so that they don't make bigger mistakes at later ages. Family is the best environment for children to get information on money management, saving and consumption habits to avoid (Martin and Olivia, 2001).

The aim of this research is to determine the opinions and activities of families regarding money management and saving awareness of their 5-6 year old children. Following questions were asked through this aim:

1. Do gender or socio-economical and educational levels of families have any impact on whether children receive allowances or have moneyboxes?

2. Do the opinions and activities, socio-economical levels or educational levels of families have any impact on money management and saving awareness of preschool children?

\section{METHOD}

The survey model is a research model to reveal and identify an existing situation (Karasar, 2005). Consequently, considering the fact that financial literacy is more effective when it is taught in early ages, families of 5-6 year old children going to preschool institutions need to determine the points to take into account regarding financial management and saving awareness. Through this purpose, a structured interview form was used with families of 945 children, 498 of whom are girls and 447 of whom are boys.

A survey form which was prepared by the researchers, used to preschoolers family. A survey form which was prepared by the researchers. The survey consists of open ended questions and closed ended questions. In analysis of the data, frequency and percentage calculations and chi square test were used in analyzing the data. As signifance levels, .05 were taken.

\section{FINDINGS and DISCUSSION}

In this study it was determined that the opinions and activities of families regarding money management and saving awareness of their 5-6 year old children.

Table 1

Activities of families regarding money management and saving awareness of their 5-6 year old children in terms of gender, educational status and socioeconomic status

\begin{tabular}{|c|c|c|c|c|c|c|c|c|c|c|c|}
\hline & & & \multicolumn{3}{|c|}{ Having moneyboxes } & \multicolumn{3}{|c|}{ Having bank account } & \multicolumn{3}{|c|}{ Getting allowance } \\
\hline & & & Yes & No & Total & Yes & No & Total & Yes & No & Total \\
\hline \multirow{7}{*}{ Gender } & \multirow{2}{*}{ Female } & $\bar{f}$ & 401 & 97 & 498 & 94 & 401 & 495 & 169 & 306 & 475 \\
\hline & & $\%$ & 80,5 & 19,5 & 100 & 19 & 81 & 100 & 35,6 & 64,4 & 100 \\
\hline & \multirow{2}{*}{ Mele } & $\mathrm{f}$ & 375 & 72 & 447 & 88 & 357 & 445 & 145 & 288 & 433 \\
\hline & & $\%$ & 83,9 & 16,1 & 100 & 19,8 & 80,2 & 100 & 33,5 & 66,5 & 100 \\
\hline & \multirow{3}{*}{ Total } & $\mathrm{f}$ & 776 & 169 & 945 & 182 & 758 & 940 & 314 & 594 & 908 \\
\hline & & $\%$ & 82,1 & 17,9 & 100 & 19,4 & 80,6 & 100 & 34,6 & 65,4 & 100 \\
\hline & & & \multicolumn{3}{|c|}{$\mathrm{X}^{2}=0,093 \quad \mathrm{p}=0,41$} & \multicolumn{3}{|c|}{$\mathrm{X}^{2}=1,82 \mathrm{p}=0,103$} & \multicolumn{3}{|c|}{$\mathrm{X}^{2}=1,296 \mathrm{p}=0,52$} \\
\hline \multirow{7}{*}{ Educational status } & \multirow[t]{2}{*}{ Primary school } & $\mathrm{f}$ & 31 & 22 & 53 & 2 & 50 & 52 & 20 & 30 & 50 \\
\hline & & $\%$ & 57,7 & 42,3 & 100 & 3,9 & 96,1 & 100 & 40,8 & 59,2 & 100 \\
\hline & \multirow{2}{*}{$\begin{array}{l}\text { Secondary } \\
\text { school }\end{array}$} & $\mathrm{f}$ & 44 & 13 & 57 & 7 & 48 & 55 & 23 & 32 & 55 \\
\hline & & $\%$ & 77,2 & 22,8 & 100 & 12,7 & 87,3 & 100 & 41,8 & 58,2 & 100 \\
\hline & \multirow[t]{2}{*}{ High School } & $\mathrm{f}$ & 291 & 57 & 348 & 51 & 295 & 346 & 132 & 201 & 333 \\
\hline & & $\%$ & 83,6 & 16,4 & 100 & 14,7 & 85,3 & 100 & 39,6 & 60,4 & 100 \\
\hline & Under graduate & $\mathrm{f}$ & 374 & 70 & 444 & 110 & 334 & 444 & 127 & 302 & 429 \\
\hline
\end{tabular}


Başal, H. A., \& Taner Derman, M. (2016). Opinions and activities of families regarding money management and saving awareness. International Journal of Human Sciences, 13(1), 957-964. doi:10.14687/ijhs.v13i1.3639

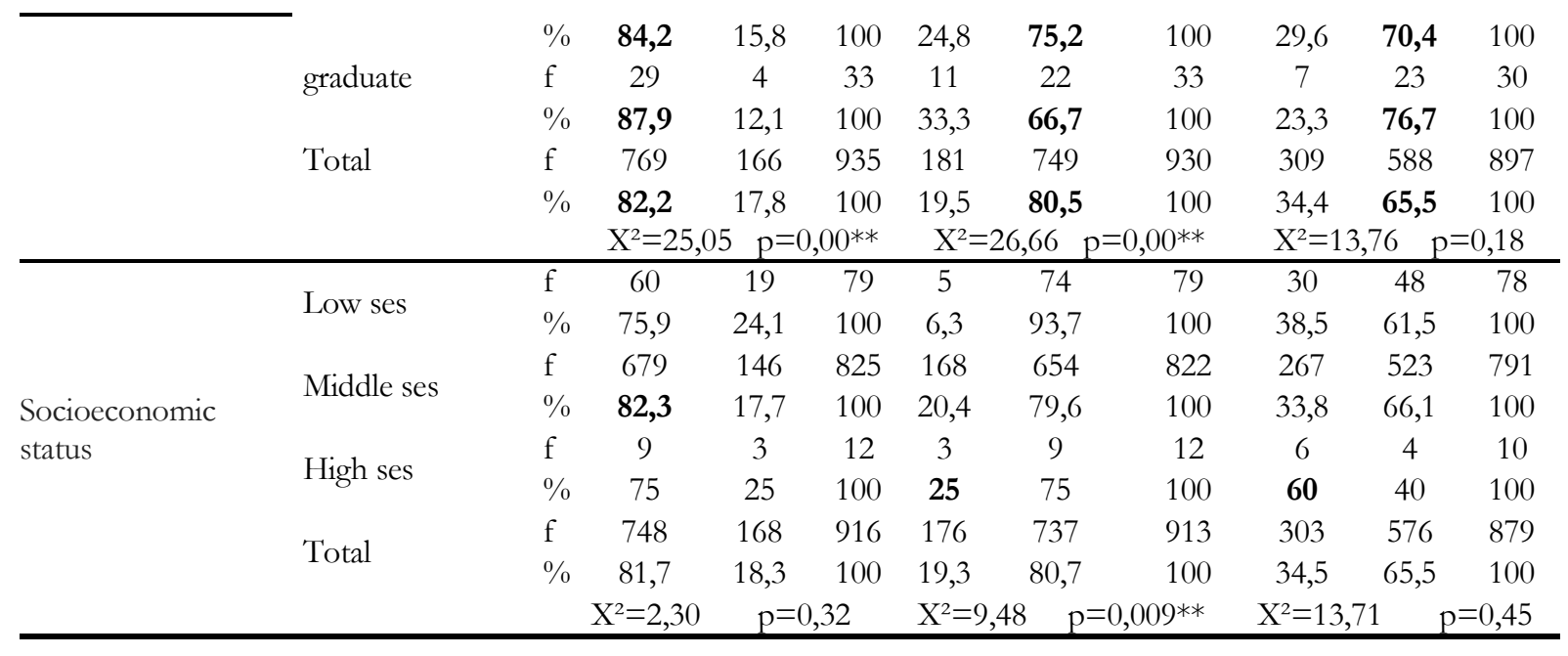

It was determined that $82 \%$ of preschoolers had moneyboxes and $19,4 \%$ of them had saving accounts in banks and 34,6\% of them received allowances. It is seen that most of preschoolers don't have a bank account and they don't receive an allowance.

It was determined that $57,7 \%$ of children whose parents have educational background at primary school level, $77,2 \%$ of children whose parents have educational background at secondary school level, $83,4 \%$ of children whose parents have educational background at high school level, $84,2 \%$ of children whose parents have educational background at university level and $87,9 \%$ of children whose parents have educational background at postgraduate level have moneyboxes.

It was determined that $96 \%$ of children whose parents have educational background at primary school level, $87,3 \%$ of children whose parents have educational background at secondary school level, $85,3 \%$ of children whose parents have educational background at high school level, $75 \%$ of children whose parents have educational background at university level and $66,7 \%$ of children whose parents have educational background at postgraduate level have moneyboxes.

It was determined that $59 \%$ of children whose parents have educational background at primary school level, $58 \%$ of children whose parents have educational background at secondary school level, $60,4 \%$ of children whose parents have educational background at high school level, $70,4 \%$ of children whose parents have educational background at university level and $76,7 \%$ of children whose parents have educational background at postgraduate don't get an allowance.

As a result of chi square test, it was seen that educational backgrounds of parents have a direct impact on whether children have bank accounts or moneyboxes. It is seen that having a moneybox or bank account gets more common as the educational level of the parents goes higher. It is also seen that getting an allowance gets less common as the educational level goes high but this situation doesn't lead to a statistically significant difference.

It is expressed that most children are ready and eager to learn on trade of products at 3 , and they can start saving at 5 (Roosevelt, 2005: Cit. Ersoy, 2008). Accordingly, giving children allowances at early ages is considered one of the best ways to teach money management skills (Nathan, 2005: Cit. Ersoy, 2008). Families give information on product quality and price-quality relation to their children and let them develop abilities to make budgets by giving them an allowance (Odabassı and Barış, 2007).

It was determined that $76 \%$ of preschool students with low socio-economical levels, $82 \%$ of preschool students with medium socio-economical levels and $75 \%$ of preschool students with high socio-economical levels have moneyboxes.

It was determined that $93,7 \%$ of preschool students with low socio-economical levels, $80 \%$ of preschool students with medium socio-economical levels and $75 \%$ of preschool students with high socio-economical levels don't have bank accounts. As a result of chi square analysis, it is seen that socio-economical level of families has a direct impact on the state of having a bank account. It was 

awareness. International Journal of Human Sciences, 13(1), 957-964. doi:10.14687/ijhs.v13i1.3639

determined that having a bank account gets more common as the socio-economical levels goes higher.

It was determined that $61,5 \%$ of preschool students with low socio-economical levels, $66 \%$ of preschool students with medium socio-economical levels and $40 \%$ of preschool students with high socio-economical levels don't get an allowance.

Table 2

Opinions of families regarding money management and saving awareness of their 5-6 year old children in terms of socioeconomic status and educational status

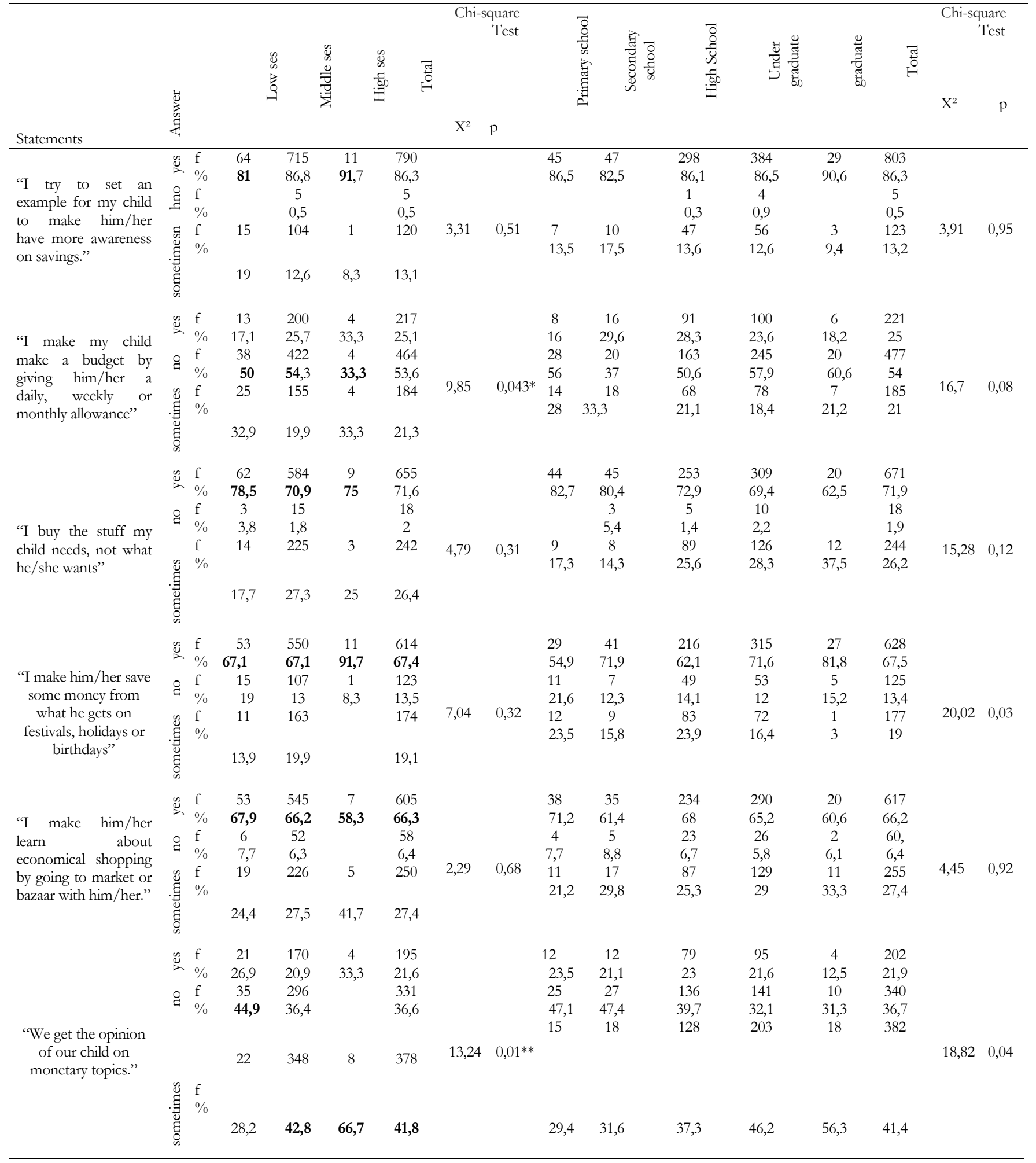


Başal, H. A., \& Taner Derman, M. (2016). Opinions and activities of families regarding money management and saving awareness. International Journal of Human Sciences, 13(1), 957-964. doi:10.14687/ijhs.v13i1.3639

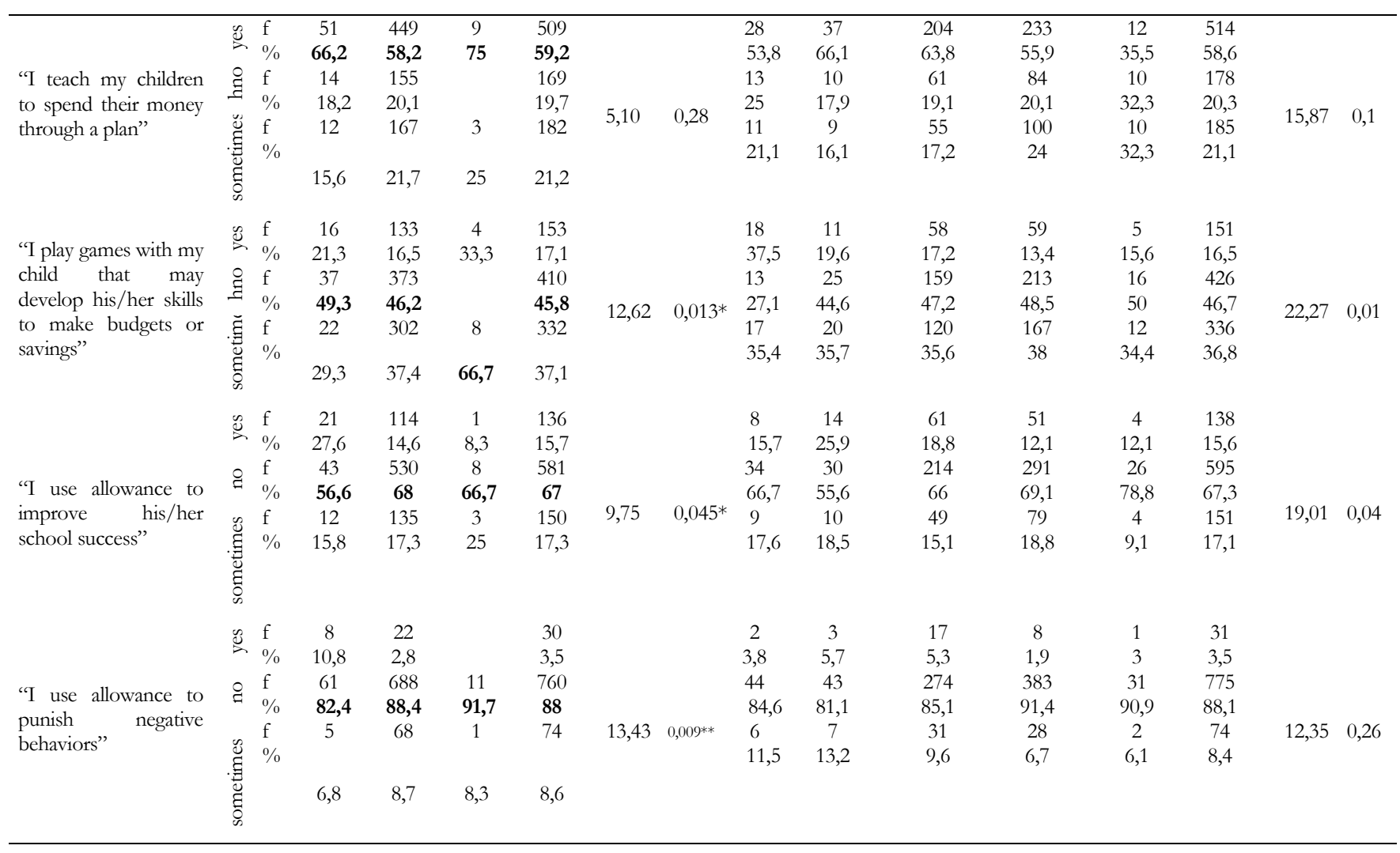

$86,3 \%$ of parents with children in preschools, $81 \%$ of parents with low socio-economical levels, $87 \%$ of parents with middle socio-economical levels and $92 \%$ of parents with high socioeconomical levels; also $86,5 \%$ of parents who graduated from primary schools, $82,5 \%$ of parents who graduated from secondary schools, $86,1 \%$ of parents who graduated from high schools, $90,6 \%$ of parents who graduated from universities and $86,3 \%$ of parents who graduated from postgraduate programs express that they try to set example for their children. In a research conducted by Bayram (2015), it was stated that money spending and managing habits of university students come from families to a large extent $(86,2 \%)$.

$53,6 \%$ of parents with children in preschools, $50 \%$ of parents with low socio-economical levels, $54,3 \%$ of parents with middle socio-economical levels and $33,3 \%$ of parents with high socioeconomical levels gave no answer to the statement "I make my child make a budget by giving $\mathrm{him} /$ her a daily, weekly or monthly allowance". As a result of chi square analysis, it can be said that children from families with high socio-economical levels have more awareness on making budgets. If we look from the viewpoint of educational level, it is seen that $56 \%$ of parents who graduated from primary schools, $37 \%$ of parents who graduated from secondary schools, $50,6 \%$ of parents who graduated from high schools, $57,9 \%$ of parents who graduated from universities and $60,6 \%$ of parents who graduated from postgraduate programs gave the answer "no" to the statement "I make him/her make a budget".

In the research conducted by Bayram (2015), it was seen that $65 \%$ of university students make budgets.

It is wise to give children the responsibility to manage their own money especially in preschool period in order to raise their awareness on money management and saving matters (Horan, 2005: Cit. Ersoy, 2008).

$71,6 \%$ of parents with children in preschools, $78,5 \%$ of parents with low socio-economical levels, $70,9 \%$ of parents with middle socio-economical levels and $75 \%$ of parents with high socioeconomical levels; also $82,7 \%$ of parents who graduated from primary schools, $80,4 \%$ of parents who graduated from secondary schools, $72,9 \%$ of parents who graduated from high schools, $69,4 \%$ 
Başal, H. A., \& Taner Derman, M. (2016). Opinions and activities of families regarding money management and saving awareness. International Journal of Human Sciences, 13(1), 957-964. doi:10.14687/ijhs.v13i1.3639

of parents who graduated from universities and $62,5 \%$ of parents who graduated from postgraduate programs expressed that they buy the stuff their children need, not they want.

$67,4 \%$ of parents with children in preschools, $67,1 \%$ of parents with low socio-economical levels, $67,1 \%$ of parents with middle socio-economical levels and $91,7 \%$ of parents with high socioeconomical levels; also $54,9 \%$ of parents who graduated from primary schools, $71,9 \%$ of parents who graduated from secondary schools, $62,1 \%$ of parents who graduated from high schools, $71,6 \%$ of parents who graduated from universities and $81,8 \%$ of parents who graduated from postgraduate programs stated that they make him/her save some money from what he gets on festivals, holidays or birthdays. It was seen as a result of chi square analysis that educational levels of families lead to a significant difference on making children save some money from what they get on festivals, holidays or birthdays.

In the research conducted by Bayram (2015) it was stated that saving money is not so common even among university students (40\%).

$66,3 \%$ of parents with children in preschools, $67,9 \%$ of parents with low socio-economical levels, $66,2 \%$ of parents with middle socio-economical levels and $58,3 \%$ of parents with high socioeconomical levels; also $71,2 \%$ of parents who graduated from primary schools, $61,4 \%$ of parents who graduated from secondary schools, $68 \%$ of parents who graduated from high schools, $65,2 \%$ of parents who graduated from universities and $60,6 \%$ of parents who graduated from postgraduate programs stated that they make their children learn about economical shopping by going to markets or bazaars with them.

$41,8 \%$ of parents with children in preschools, $42,8 \%$ of parents with middle socio-economical levels and $66,7 \%$ of parents with high socio-economical levels stated that they sometimes get the opinions of their children on monetary topics; while $21,6 \%$ of parents with children in preschools, $26,9 \%$ of parents with low socio-economical levels, $20,9 \%$ of parents with middle socio-economical levels and $33,3 \%$ of parents with high socio-economical levels stated that they always get the opinions of their children on monetary topics. On the other hand, 44,9\% of families with low socio-economical levels stated that they don't get the opinions of their children on monetary topics. As a result of chi square analysis, it is seen that there are socio-economical differences on getting the opinions of children on monetary topics. It was established that the most sensible parents on this matter are parents from high socio-economical levels while the least sensible families are from low socio-economical levels. If we look from the viewpoint of educational level, it is seen that $47,1 \%$ of parents who graduated from primary schools, $47,4 \%$ of parents who graduated from secondary schools, $39,7 \%$ of parents who graduated from high schools, $32,1 \%$ of parents who graduated from universities and $31,3 \%$ of parents who graduated from postgraduate programs gave the answer "no". It can be said as a result of chi square analysis that parents who graduated from primary schools and secondary schools are less sensible on getting the opinions of children on monetary topics.

$59,2 \%$ of parents with children in preschools, $66,2 \%$ of parents with low socio-economical levels, $58,2 \%$ of parents with middle socio-economical levels and $75 \%$ of parents with high socioeconomical levels; also 53,8\% of parents who graduated from primary schools, $66,1 \%$ of parents who graduated from secondary schools, $63,8 \%$ of parents who graduated from high schools, $55,9 \%$ of parents who graduated from universities and $35,9 \%$ of parents who graduated from postgraduate programs expressed that they taught their children to spend their allowances through planning.

$45,8 \%$ of parents with children in preschools, $49,3 \%$ of parents with low socio-economical levels, $46,2 \%$ of parents with middle socio-economical levels stated that they play games with their children that may develop their skills to make budgets or saving; while $66,7 \%$ of parents with high socio-economical levels stated that they sometimes play these games and 33,3\% stated that they always play. As a result of chi square analysis, it was determined that parents with higher socioeconomical levels are more sensible on playing games with their children that may develop their skills to make budgets or savings while parents with lower socio-economical levels are less sensible. If we look from the viewpoint of educational level, it was seen that $37,5 \%$ of parents who 
Başal, H. A., \& Taner Derman, M. (2016). Opinions and activities of families regarding money management and saving awareness. International Journal of Human Sciences, 13(1), 957-964. doi:10.14687/ijhs.v13i1.3639

graduated from primary schools gave the answer "no" while 55,6\% of parents who graduated from secondary schools, $47,2 \%$ of parents who graduated from high schools, $48,5 \%$ of parents who graduated from universities and $50 \%$ of parents who graduated from postgraduate programs gave the answer "no". It can be said as a result of chi square analysis that parents who graduated from primary schools are more sensible on playing game with their children that may develop their skills to make budgets or savings.

$67 \%$ of parents with children in preschools, $56,6 \%$ of parents with low socio-economical levels, $68 \%$ of parents with middle socio-economical levels and $66,7 \%$ of parents with high socioeconomical levels stated that they don't use their children's allowances for school success. It can be said as a result of chi square analysis that parents with lower socio-economical levels are less sensible on using allowance for school success. If we look from the viewpoint of educational level, it is seen that $66,7 \%$ of parents who graduated from primary schools, $55,6 \%$ of parents who graduated from secondary schools, $66 \%$ of parents who graduated from high schools, $78,8 \%$ of parents who graduated from universities and $67,3 \%$ of parents who graduated from postgraduate programs gave the answer "no". It can be said as a result of chi square analysis that parents who graduated from postgraduate programs are more sensible on using allowance for school success.

$88 \%$ of parents with children in preschools, $82,4 \%$ of parents with low socio-economical levels, $88,4 \%$ of parents with middle socio-economical levels and $91,7 \%$ of parents with high socioeconomical levels stated that they don't use their children's allowances to punish negative behaviors. It can be said as a result of chi square analysis that parents with lower socio-economical levels are less sensible on using allowance to punish negative behaviors. If we look from the viewpoint of educational level, it is seen that $84,6 \%$ of parents who graduated from primary schools, $81,1 \%$ of parents who graduated from secondary schools, $85,1 \%$ of parents who graduated from high schools, $91,4 \%$ of parents who graduated from universities and $90,9 \%$ of parents who graduated from postgraduate programs gave the answer "no".

According to Estess and Barocas (1994), there must not be a connection between allowance and school work and no payment must be paid for homeworks or better grades. Levin and Ryan (1995) state that cutting off their allowances to punish negative behaviors is wrong and people tend to mix discipline with money management.

\section{RECOMMENDATIONS}

Courses on monetary management, saving awareness and financial literacy must be given in educational institutions starting from preschools. Educational games must be involved in preschool education to create awareness on money management and saving awareness. Seminars must be conducted for families on money management, financial literacy and the ways to teach these to children.

\section{REFERENCES}

Bayram, S. S. (2015). "Financial literacy and money management behaviours: Application on students of Anadolu University", Business \& Management Studies: An International Journal,2 (2), 105-135.

Çakmak, A. Ç. \& Çakır, M. (2013). "The primary schoool students who are aged 9-11 effect of purchase decisions in the family: A research in city center Karabuk", Journal of Niğde University EASF, 6 (1), 116-136.

Ersoy, S. (2008). "Parent guidance in teaching money management to children", Journal of Sakarya University Education Faculty, 15, 140-157

Estess, P. S. \& Barocas, I. (1994). Kids, money and values: Creative ways to teach your kids about money. Cincinnati: Betterway Books. 
Başal, H. A., \& Taner Derman, M. (2016). Opinions and activities of families regarding money management and saving awareness. International Journal of Human Sciences, 13(1), 957-964. doi:10.14687/ijhs.v13i1.3639

Lewin, E. S. \& Ryan Jr, B. (1995). How to raise money-smart kids. Your Money, 16 (6), http://www.kidsmoney.org/allart5.htm

Karasar, N. (2005). Scientific Research Method. Ankara: Nobel Publishing.

Kır, I. (2010), "Eğitimin toplumsal temelleri”, Eğitim Bilimine Giriş, Edt. Fatih Töremen, İstanbul: İdeal Kültür Yayıncilık.

Martin, A.\& Oliva, J.S. (2001). Teaching children about money: Applications of social learning and cognitive learninig devolopmental theories. Journal of Family and Consumer Sciences, 93(2), 2629 .

Odabaşı, Y. \& Barış, G. (2007). Tüketici Davranısıı. İstanbul: MediaCat Kitapları.

Wagland, S. (2006). "Financial Literacy in the context of literacy in general", 5. Australian Society of Heterodox Economists Conference, 11-12 December 2006, Kensington, New South Wales. 